\title{
The first finding of Mimomys in the Russian Far East
}

Mikhail P. Tiunov, Fedor N. Golenishchev, and Leonid L. Voyta

Acta Palaeontologica Polonica 61 (1), 2016: 205-210 doi:http://dx.doi.org/10.4202/app.00082.2014

A new species of the Mimomys is described from the Far East Russia (the Medvezhyi Klyk cave, Sikhote-Alin). Layer 7 of the Medvezhyi Klyk cave (1.08-1.18 m) was dated to be 13

790-14 200 BP. Mimomys chandolensis sp. nov. was found in a deeper layer (2.63-2.68 m) and therefore assuming there was no redeposition of the remains and that the accumulation proceeded gradually, the molar specimen we found is 30-50 kyr old. Due to the extent of the preservation we observed in the molar and the structure of the cave, the specimen does not seem likely to have been redeposited. Our hypothesis is that due to the warm and wet climate of the region, the vole, which became extinct more than $600 \mathrm{kyr}$ ago, had been extant there by the Late Pleistocene period. The new species is hypsodont, with a few cement, a lack of enamel isle or prismatic fold; tangential and lamellar layers of enamel ultrastructure are poorly expressed.

Mikhail P. Tiunov [tiunov@ibss.dvo.ru, TIUNOV@biosoil.ru], Institute of Biology and Soil FEB RAS, Prospekt 100-letia 159, 690022 Vladivostok, Russian Federation; Fedor N. Golenishchev[f gol@mail.ru], Zoological Institute of RAS, Universitetskaya emb., 1, 199034 St.-Petersburg, Russian Federation; Leonid L. Voyta [desmana.zin@gmail.com], Zoological Institute of RAS, Universitetskaya emb., 1, 199034 St.-Petersburg, Russian Federation; Institute of Natural Resources, Ecology and Cryology SD RAS, Butina st., 26, 672090 Chita, Russian Federation.

This is an open-access article distributed under the terms of the Creative Commons Attribution License (for details please see creativecommons.org), which permits unrestricted use, distribution, and reproduction in any medium, provided the original author and source are credited. 
